\title{
LIVER FUNCTION AS TESTED BY THE LIPEMIC CURVE AFTER INTRAVENOUS FAT ADMINISTRATION ${ }^{1}$
}

\author{
By ARTHUR NACHLAS, G. LYMAN DUFF, HERBERT C. TIDWELL AND \\ L. EMMETT HOLT, JR. \\ (From the Departments of Pediatrics and Pathology, Johns Hopkins University School of \\ Medicine, Baltimore)
}

(Received for publication September 25, 1935)

That the liver plays an important rôle in fat metabolism has long been known. On the one hand, it secretes bile which aids the digestion and absorption of fats, and on the other, there is evidence (1) that it plays a primary rôle in removing from the circulation fat which has entered from the chyle or has been mobilized from depots. The subsequent fate of this fat in the liver has been the subject of controversy. According to the well known theory of Leathes and Meyer-Weddell (2) fatty acids undergo desaturation in the liver, and triglycerides are converted into phospholipids; these changes are thought to be necessary before the fat can be utilized. The latter change is supported by firmer experimental evidence than the former (3).

From the pathological side, there is evidence to show that the liver is intimately concerned in the intermediary metabolism of fats, for in certain conditions associated with hepatic damage there occurs a striking accumulation of fat in the liver cells. It was once assumed that this was due to the transformation of unstainable fat into some stainable form, and the term " fatty degeneration" seemed appropriate. Chemical observations, however, have shown that these accumulations of fat resemble depot fat or ingested fat (4) rather than liver fat proper (elément constant); hence the condition is more properly designated as "fatty infiltration." To be sure one cannot attribute all instances of fatty liver to impaired hepatic function. There are obscure cases in which this condition appears to run in families (5); it is also likely that a fatty liver may be produced by an excessive load thrust upon a normal organ. On the other hand, absence of necrosis and of abnormalities in the familiar function tests does not prove that the organ is functionally normal. It may be that the function dealing with the inter-

1 Aided by a grant for the study of fat metabolism from Mead Johnson and Company, Evansville, Indiana. mediary metabolism of fats is alone affected. From our present knowledge of hepatic functions it appears that these can and often do vary quite independently of each other. Special interest has attached to this particular function of the liver since the discovery of Best and his collaborators (6) that the deposition of fat in the liver was controlled by a specific mechanism; they found that the administration of choline and of certain choline derivatives served to prevent the development of a fatty liver.

In view of the recognized importance of the liver in fat metabolism it is not surprising to find that various attempts have been made to gain information about the liver from a study of fat metabolism-balance studies, observations on fasting lipemia and on the alimentary lipemic curve (7) have been employed. Balance studies may yield some information as to fat digestion and absorption, but observations on lipemia-despite the claims that have been made for them-have not proved of particular clinical value. The level of the blood fat is the resultant of the rate of introduction and of removal of fat from the blood. An incompetent liver may affect the introduction of fat in the chyle as well as its rate of removal. Both of these factors may be adversely affected without altering the level of the blood fat. In fact, any pathological condition interfering with digestion or absorption from the intestine may mask impaired ability of the liver to remove fat from the blood.

It has seemed to us that the function of the liver in the utilization of fat could be more accurately studied by means of the lipemic curve after the intravenous administration of fat. This would eliminate the variable factor of the rate of introduction of fat in the chyle, and should prove a far more delicate test than the level of fasting lipemia alone. Our interest in this problem developed from the observations of Holt, Tidwell and 
Scott (8) who had given intravenous injections of fat for therapeutic purposes and noted the rather frequent occurrence of fatty liver in a small series of autopsies. It seemed likely that in such instances the liver might not be capable of handling the fat so introduced, and that further intravenous administration would then be contraindicated. Presumably, a liver unable to utilize fat would be limited in its capacity to remove fat from the blood, and this would be reflected in the lipemic curve after intravenous fat administration. It was in the hope of developing a clinical test of the ability of the liver to utilize fat that the present study was undertaken. We attempted in experimental animals to damage the liver with an agent which causes a necrosis of the liver characteristically associated with the accumulation of fat in liver cells in order to see if this state of affairs would be reflected in the lipemic curve. The present report deals with a series of dogs poisoned with carbon tetrachloride. In these animals we were able to show that accompanying the injury to the liver there developed a difficulty in removing intravenously injected fat from the blood.

\section{EXPERIMENTAL TECHNIQUE}

The observations on the lipemic curve were carried out after the injection of a fine emulsion of fat. The emulsion used was an aqueous suspension containing 6 to 8 per cent total lipids, two-thirds of which consisted of olive oil and one-third of purified egg lecithin; it was homogenized at 4000 pounds pressure, sterilized by autoclaving, and rendered isotonic by dilution with an appropriate amount of concentrated saline just before use. Practically all the particles were less than $2 \mu$ in diameter, only an occasional one as large as $3 \mu$ being present. It has been shown (9) that, unless such fine emulsions are used, appreciable amounts of fat are caught in the lung capillaries. The fat so introduced (10) does not appear in the phagocytic cells of the reticulo-endothelial system, but can be identified, if at all, only in the parenchymatous cells of the liver and other organs, just as is the case with the fat entering naturally in the chyle. For following the lipemia we employed the Gage and Fish method (11) of counting the visible fat particles in a unit field with the ultramicroscope. This is a more convenient and rapid procedure than the microchemical estimation of fat, and has been found (12) to give comparable results.

Small dogs were used as experimental subjects. The test injections were made after a fast of fifteen to twenty hours, in order to avoid the complication of alimentary lipemia. The test dose given was one-half gram total lipid per kilogram in all but Dog $A$ which received 1 gram per kilogram. This was injected during the course of ten to fifteen minutes, observations on the blood fat being made before the injection, immediately following it, and at regular intervals thereafter. This procedure was followed in all the animals excepting Dog A which received the large quantity of $\mathrm{fat}$; in this animal the first reading after the injection was made after a lapse of one hour. The carbon tetrachloride was given by stomach tube in all instances. Animals were sacrificed within 24 hours after the last test curve.

The lipemic curves obtained are shown in the accompanying figures. The chylomicron counts on the last three dogs were done with a slightly different technique from that employed with the first three dogs-one which yielded slightly lower values.

\section{PROTOCOLS}

Dog. A. Weight $2.5 \mathrm{kgm}$. This animal was given increasing doses of carbon tetrachloride up to $10 \mathrm{cc}$. per kilo as shown in Figure 1. Like the others, he showed marked salivation, tremors and a certain amount of shock after each dose; he also vomited on every such occasion. Estimations of the amount of the drug lost in the vomitus were not made, but the resulting loss probably accounts for the apparently large dose of the drug required to produce metabolic effects. When the dose was raised to $10 \mathrm{cc}$. per kilo a definite elevation of the lipemic curve resulted; the curve continued to rise for several days and then to return toward normal. A repetition of the large dose caused a second rise of the lipemic curve. The animal was then sacrificed. Autopsy showed a liver of normal size with areas of fresh central necrosis and moderate fat infiltration about the necrotic areas. In addition there was a chronic process as evidenced by the presence of macrophages and beginning healing. The periportal cells appeared quite normal.

$\operatorname{Dog} B$. (Figure 1.) Weight $4.2 \mathrm{kgm}$. This animal, like $\operatorname{Dog} A$, vomited whenever the drug was given, and hence the dosages recorded are doubtless well in excess of those he actually received. A marked rise in the lipemic curve followed the administration of $10 \mathrm{cc}$. of the drug per kilogram. When the dose was reduced, the curve tended to return to normal and to rise again when it was again increased. Autopsy showed a somewhat cirrhotic liver with distinct fibrosis of the central areas together with some fresh necrosis of the remaining central liver cells. The midzonal liver cells showed moderate fatty infiltration. The cells around the portal spaces appeared normal.

Dog C. (Figure 2.) Weight $7.7 \mathrm{kgm}$. This animal did not vomit the drug. After $4 \mathrm{cc}$. per kilogram of carbon tetrachloride he showed a slight abnormality of the lipemic curve, but the curve subsequently returned to normal. With increasing doses a progressive rise in the lipemic curve took place. Autopsy showed a liver of normal size with relatively slight central necrosis and moderate numbers of fat-containing vacuoles in the central liver cells. The greater portion of each lobule was normal. 


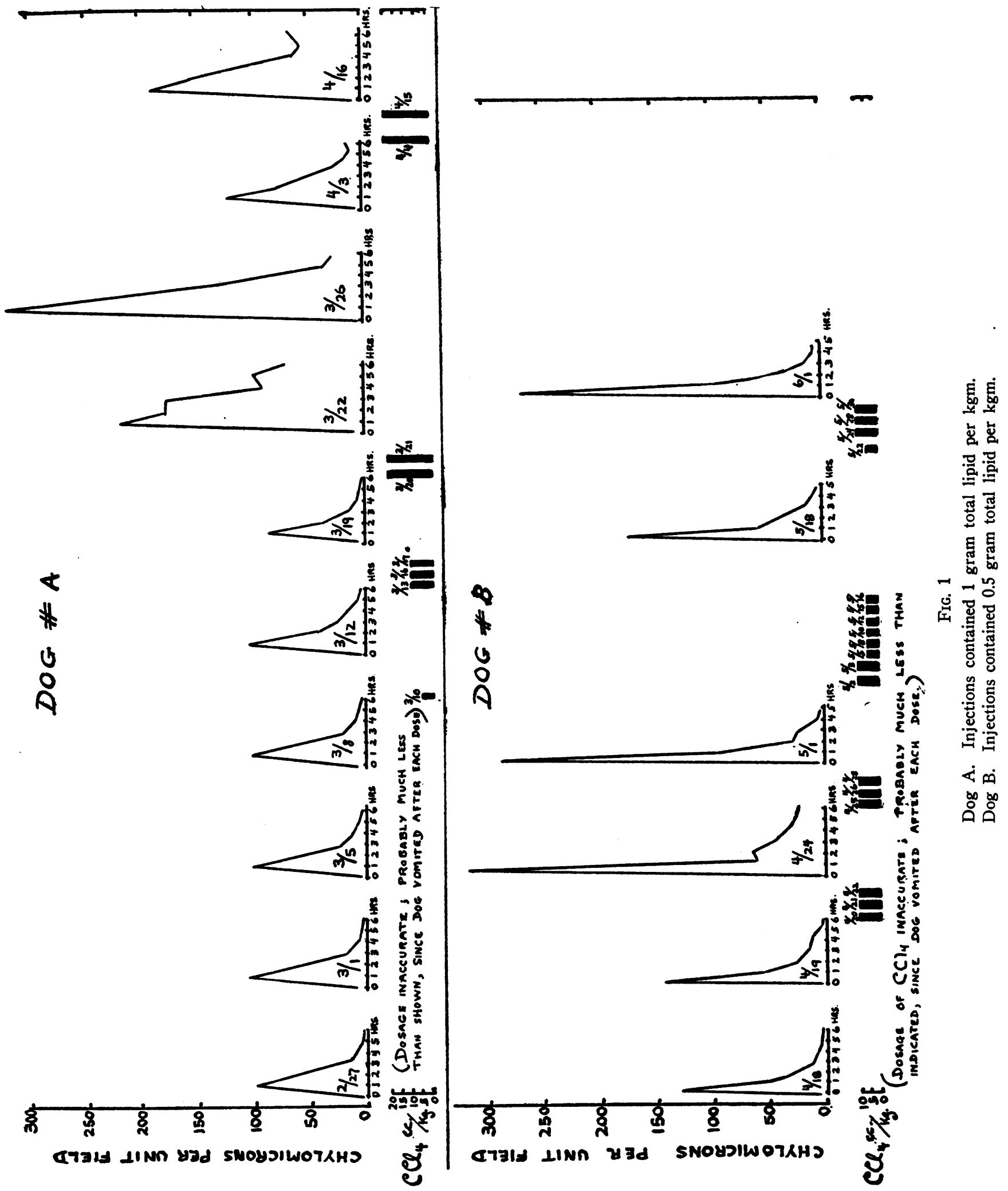




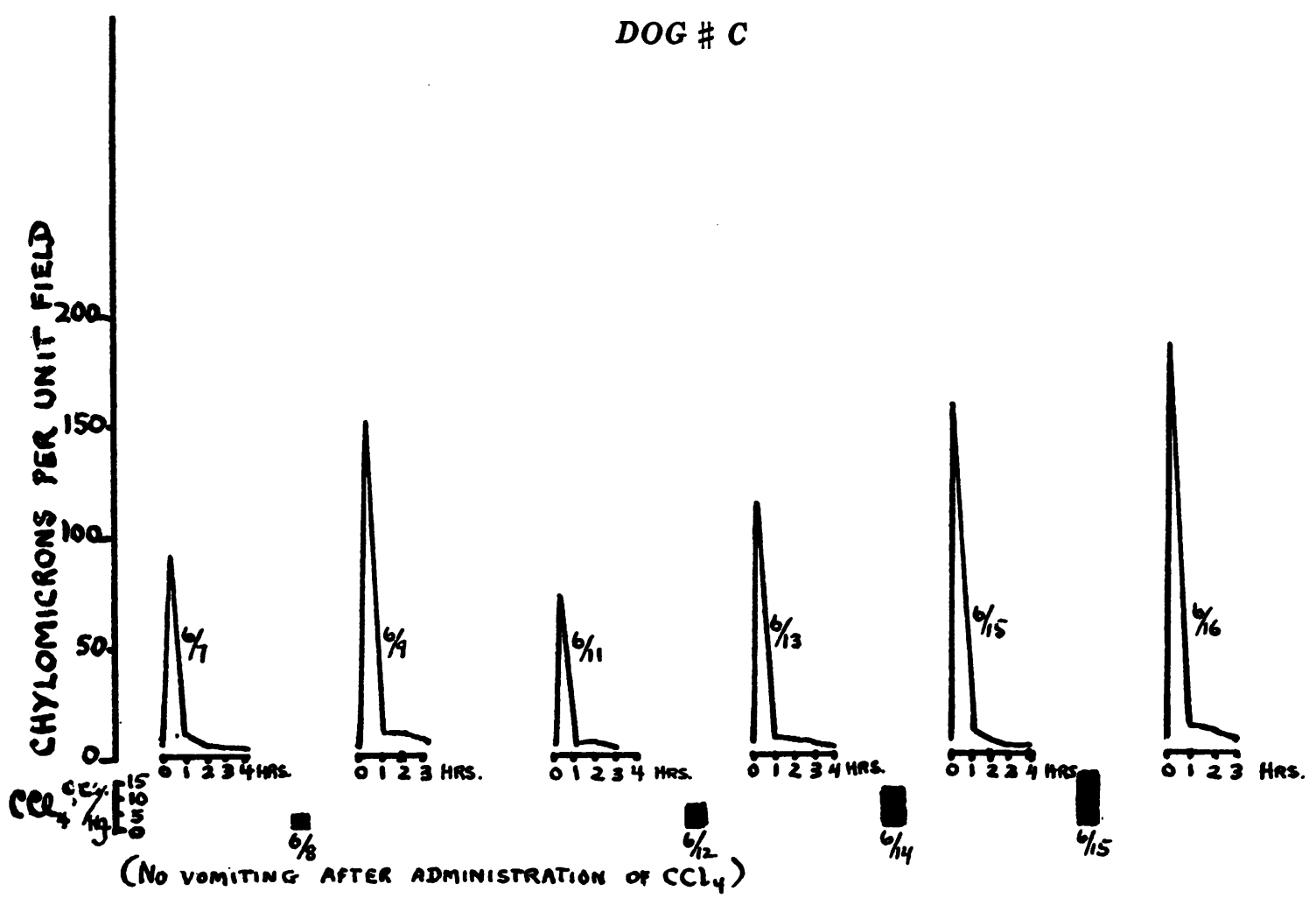

Fig. 2

Dog C. Injections contained 0.5 gram total lipid per $\mathrm{kgm}$.

Owing to the difficulty experienced with vomiting after the administration of carbon tetrachloride, the technique was varied. In the following three animals carbon tetrachloride was given with an equal amount of alcohol. As was shown by Lamson et al. $(14,15)$, alcohol increases the toxicity of the drug making it possible to diminish the dose. In Dog D even this method of administration failed to prevent vomiting each time the drug was given; the dosage as given is, therefore, highly inaccurate. In Dogs $E$ and $F$ carbon tetrachloride and alcohol were given in fractional doses extending over a period of six hours. No vomiting at all took place under these circumstances.

Dog D. (Figure 3.) Weight $6.5 \mathrm{kgm}$. This animal after one dose of $4 \mathrm{cc}$. each $\mathrm{CCl}_{4}$ and alcohol (partly vomited) showed a distinct elevation of the lipemic curve. A second smaller dose (also partly vomited) increased the height of the curve. Subsequently the curve returned toward normal. Following a third dose the animal died. Autopsy showed small areas of collapse with slight scarring in the central areas of the liver lobules. This was evidently the result of the injury from the doses given two weeks before death. In addition, the intact liver cells were somewhat swollen and granular; many of them contained vacuoles of fat. It appears probable that this was the result of the last dose of carbon tetrachloride which was not vomited, from which the dog died.

Dog E. (Figure 4.) Weight $5.2 \mathrm{kgm}$. This animal received a single dose of carbon tetrachloride and alcohol (1 cc. each per kilo) which was completely retained. A marked elevation of the lipemic curve resulted, which gradually returned towards normal. The animal was sacrificed on the thirteenth day after the administration of the drug. Autopsy showed scarring of the central portions of the liver lobules with remnants of necrotic cells. The intact liver cells in the midzonal region contained many small vacuoles of fat which diminished gradually toward the periportal spaces.

$\operatorname{Dog} F$. (Figure 5.) Weight $6.1 \mathrm{kgm}$. This animal was given a single dose of $\mathrm{CCl}_{4}$ and alcohol (1 cc. each per kilo) which was well retained. A marked elevation of the lipemic curve was obtained. A biopsy of the liver taken at this time showed fresh central necrosis involving about half of each liver lobule. The intact cells in a zone immediately adjacent contained large vacuoles of fat. The periportal cells appeared swollen and granular.

Following this, the lipemic curve gradually returned to almost the normal level. The animal was sacrificed on the sixteenth day after the administration of the poison. Autopsy showed that most of the necrotic cells that had 


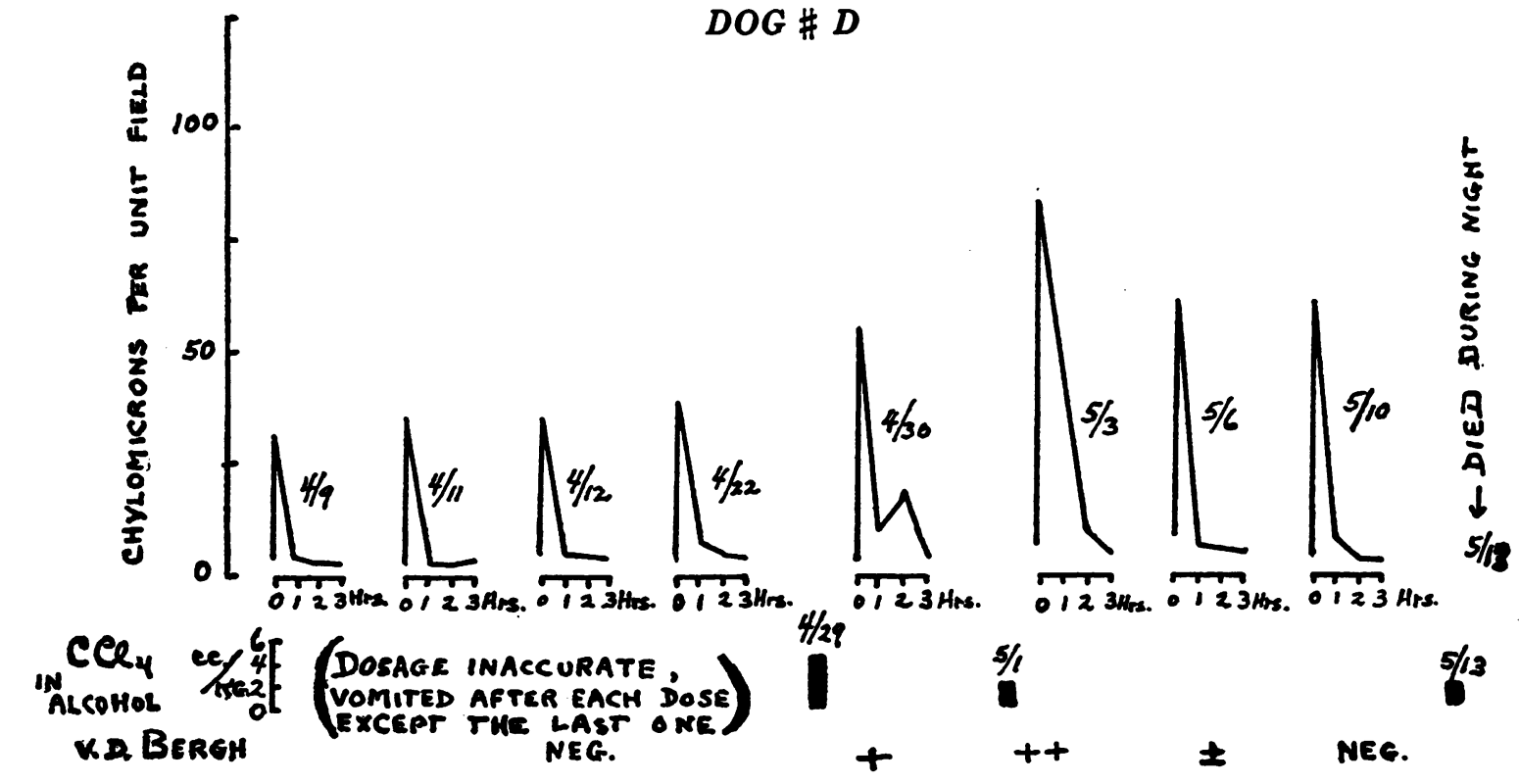

$D O G \# D$

Fig. 3

Dog D. Injections contained 0.5 gram total lipid per kgm.

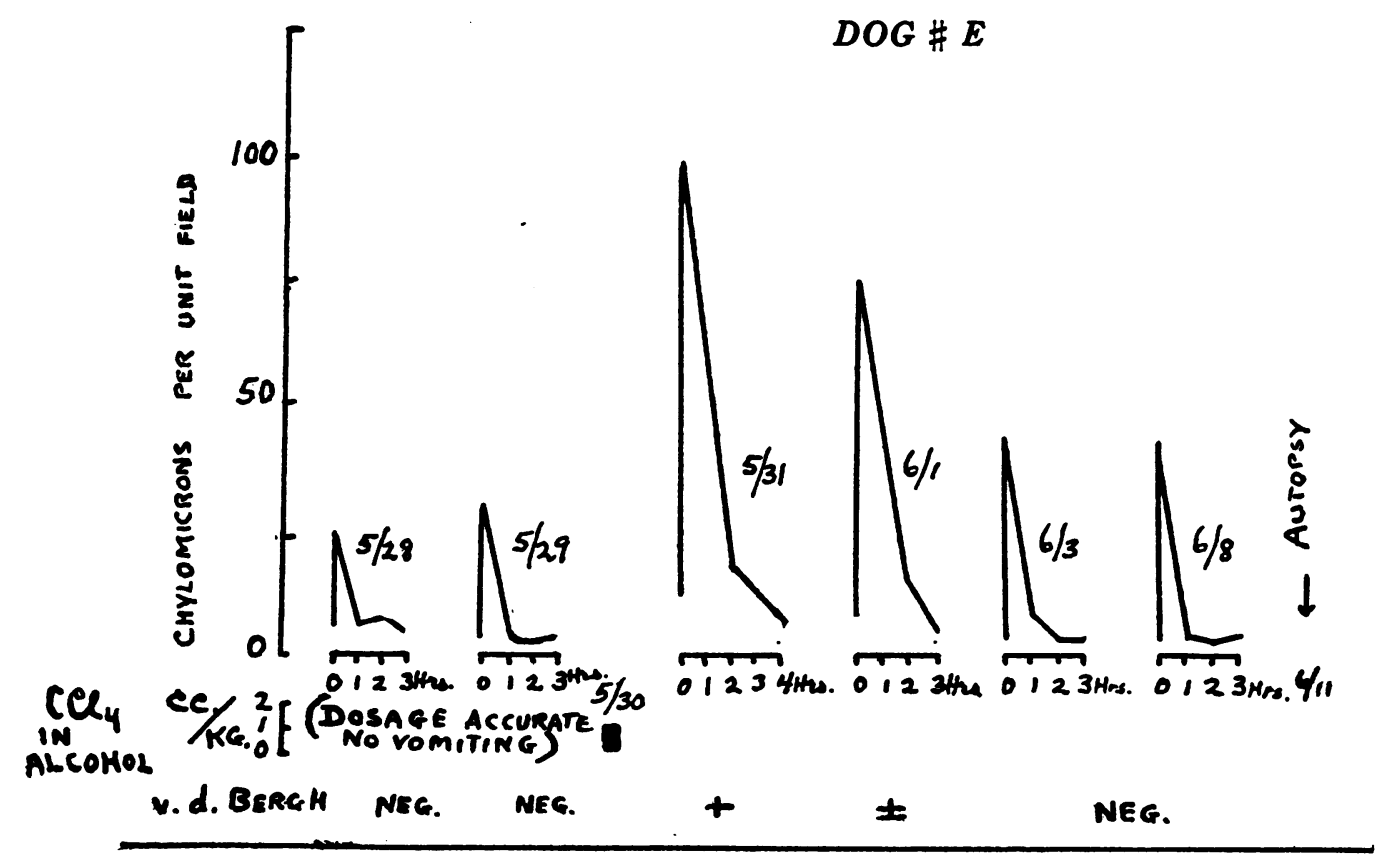

FIG. 4

Dog E. Injections contained 0.5 gram total lipid per $\mathrm{kgm}$. 


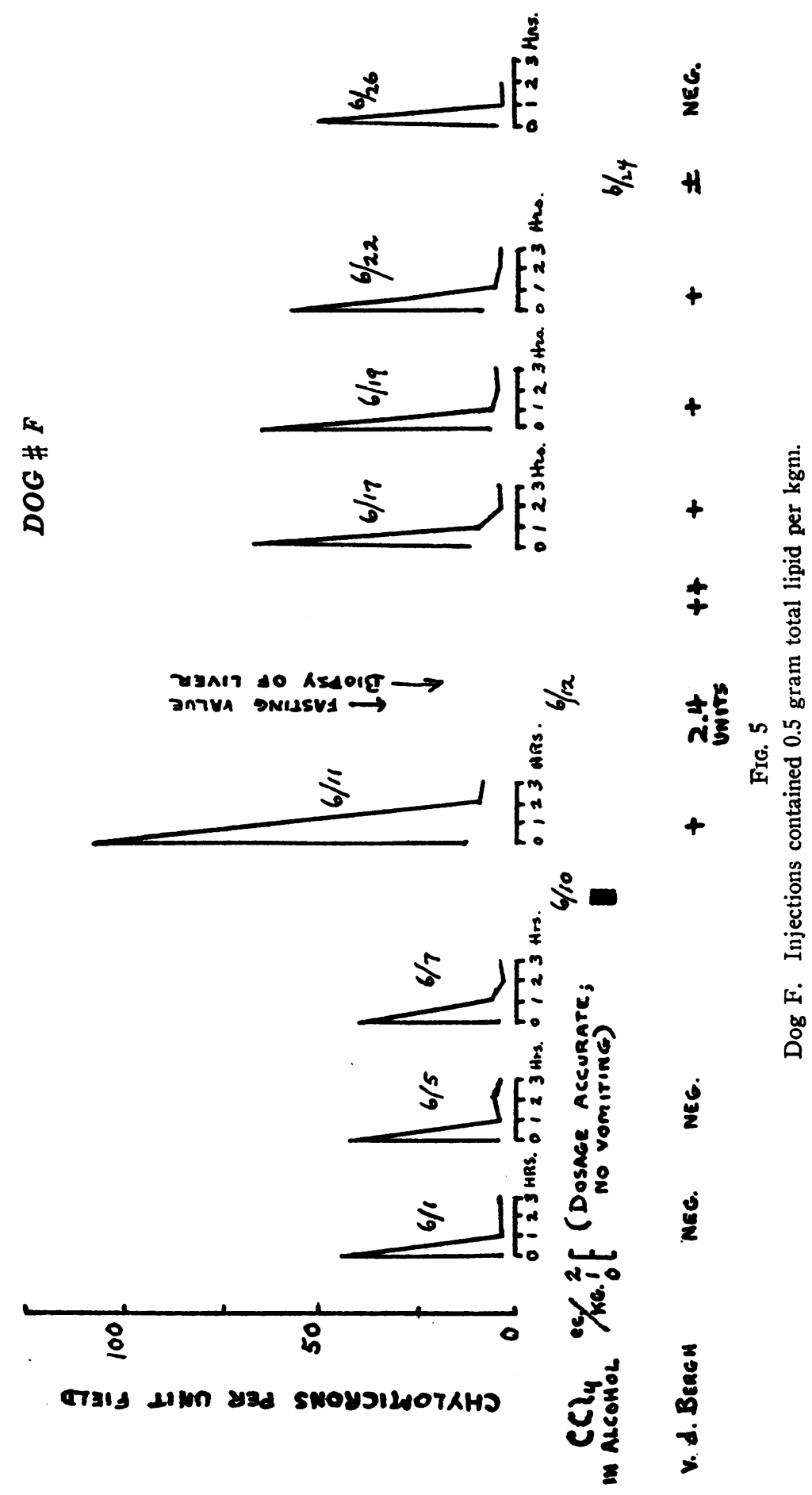


been observed at biopsy fifteen days earlier had disappeared; only a few remnants of such cells could be seen in the collapsed framework of the central part of the liver lobules. Hardly any fat was to be seen, but a few droplets were visible in the cells immediately adjacent to the scarred areas-much less, however, than in the biopsy specimen. The periportal cells were normal.

\section{DISCUSSION}

The experiments reported above indicate that doses of carbon tetrachloride which are sufficient to cause liver necrosis and visible accumulations of fat in the liver will regularly affect the lipemic curve after the intravenous injection of fat. Whether this difficulty in removing fat from the blood is due to the presence of an excess of fat in the liver which dams back fat into the blood or to some toxic action on the liver cells which prevents their removing fat from the blood it is impossible to say. It is conceivable that this effect of carbon tetrachloride is not concerned with the liver at all, but results from damage to other organs which may normally be capable of removing fat from the blood. The thesis of Leathes and MeyerWeddell (2) that conversion of fat into a utilizable form takes place primarily in the liver is certainly far. from established, and even if it were it does not follow that this is the exclusive route of removal from the blood. There are a number of observations which suggest other sites of removal for at least a portion of the fat. By introducing fats with peculiar chemical characteristics, Sato (9) was able to show that a small percentage found its way into a number of different organs. The observations of Gage and Fish (11) with stained fat pointed to this same conclusion. It was formerly maintained that fat introduced by vein was removed by the cells belonging to the reticulo-endothelial system, and indeed Saxl and Donath (13) even went so far as to employ the lipemic curye after intravenous fat injection as a test for the activity of this system. We are, however, inclined to attribute much of the early work in which fat introduced by vein was found in the phagocytic cells to the use of unphysiological preparations. Reports in the literature are very conflicting as to this point, and some observations we ourselves made in healthy dogs showed no anatomical evidence of deposition of fat in these cells unless the quantity given by vein was truly enormous $(10 b)$. We must admit that our knowledge as to the removal of fat from the blood is still incomplete, and must therefore refrain from making a positive statement in interpreting the observed effect of carbon tetrachloride as due to liver damage. Nevertheless, it seems probable to us that such is the case. Lamson and his coworkers (14) showed that when carbon tetrachloride was introduced as we have introduced it, damage was manifest only in the liver, and we are impressed with the work we have quoted above implicating the liver particularly in the disposal of fat. On the whole, the weight of evidence indicates that we are dealing with a liver function.

The experiments presented bring up several other points for discussion. In the first place, it is quite evident that the lipemic curve is a more sensitive indicator of carbon tetrachloride intoxication than is the fasting blood fat level (shown by the point of origin of each curve). In the first three dogs there was no evidence of fasting lipemia even with a markedly abnormal lipemic curve. In the last three dogs and particularly in Dog $F$ the fasting blood fat is elevated at the height of the intoxication. It may be of significance that these three dogs were the ones which received carbon tetrachloride and alcohol.

It is also worthy of comment that the lipemic curve does not run parallel to anatomical liver injury, tending to return towards normal in the face of persistent anatomical damage. Similar findings were obtained by Lamson and Wing (15) who studied liver function in carbon tetrachloride poisoning with several other functional tests. That a liver with extensive necrosis can function practically normally is well known. The improvement in function observed must occur in cells which show little or no anatomical evidence of poisoning. If the surviving liver cells were less able to utilize fat at the height of the intoxication than at a later date, one would expect to find that they contained more fat at the former period. In order to see if this was the case a biopsy was performed ${ }^{2}$ in Dog $F$ at the height of the intoxication, 48 hours after the administration of the drug. This revealed considerably more fat than was subsequently found in the liver cells at autopsy.

${ }^{2}$ By Dr. Ferdinand C. Lee of the Department of Surgery. 
It seemed of interest to make some comparisons between the lipemic curve and an established liver function test; the Van den Bergh reaction was therefore followed on the last three dogs in the series. The data, given on the charts, show a close agreement between the abnormality of the lipemic curve and the development of bilirubinemia. The change in the Van den Bergh reaction was always slight; only in one instance (Dog F) did the bilirubin reach a level that could be determined quantitatively. Although the data are too meagre to permit a definite statement as to the relative sensitiveness of the two tests, it would appear that they at least ran parallel and are of comparable sensitivity.

Whether or not this new procedure will prove of any clinical value must be left for future ${ }^{3}$ observations. $U p$ to the present time we have had the opportunity of using this test in only a single instance of liver disease in man-an infant with congenital malformation of the bile ducts, proved by operation. This subject showed a notable elevation of the lipemic curve with no increase in the fasting blood fat level.

We wish to emphasize that it is not our purpose to offer the lipemic curve after intravenous fat administration as a competitor to the more familiar tests of liver function. Such value as this test may possess lies in the fact that it provides a simple and more accurate index of a particular function than has hitherto been available.

\section{SUM MARY}

1. It is shown that the administration of carbon tetrachloride to dogs causes difficulty in removal of fat from the blood after intravenous injection.

2. Reasons are given for the belief that this phenomenon is due to liver damage caused by the drug, and it is suggested that the lipemic curve after intravenous fat may be of value in the study of liver function.

3 At the time these observations were made we were not aware of any similar studies. However, in the transactions of a current meeting of the Japanese Society of Internal Medicine (16), we have just run across a report that Komatsu has studied the lipemic curve after intravenous fat administration in a number of clinical conditions including various types of liver disease. No details of Komatsu's findings are given.

\section{BIBLIOGRAPHY}

1. Discussed in the monograph of Leathes, J. B., and Raper, H. S., The Fats. Chapter 8. The Transfer of Fat from Blood to Organs. Longman's, Green and Co., London, 1925, 2nd ed. See also Sato (9).

2. Leathes, J. B., and Weddell, L. M., On the desaturation of fatty acids in the liver. J. Physiol. (Proc.), 1909, 38, xxxviii-xl.

3. (a) Hotta, S., Die Bedeutung der hoch ungesättigten Fettsäuren in den Organen. Tohoku J. Exper. Med., 1932, 20, 65.

(b) Channon, H. J., Irving, E., and Smith, J. A. B., The fatty acids of pig liver. The octadecenoic acids and the desaturation theory. Biochem. J., 1934, 28, 840 and 1807.

(c) Sinclair, R. G., The physiology of the phospholipids. Physiol. Rev., 1934, 14, 351.

4. Evidence reviewed by Leathes and Raper (1).

5. Björum, A., The occurrence of fatty liver in families. Acta Paediat., 1926-7, 6, 225.

6. (a) Best, C. H., The rôle of the liver in the metabolism of carbohydrate and fat. Deposition of liver fat. Lancet, 1934, 1, 1274.

(b) Best, C. H., Channon, H. J., and Ridout, J. H., Choline and the dietary production of fatty livers. J. Physiol., 1934, 81, 409.

7. (a) Feigl, J., Uber das Vorkommen und die Verteilung von Fetten und Lipoiden im Blute bei Geisteskrankheiten. Biochem. Ztschr., 1918, 88, 53.

(b) Uber das Vorkommen und die Verteilung von Fetten und Lipoiden im menschlichen Blutplasma bei Ikterus und Cholämie. Biochem. Ztschr., 1918, 90, 1.

(c) Lemierre, A., Brulé, M., Weill, A., and Laudat, M., L'examen Chimique et Ultra-microscopique du Sang dans l'étude de l'absorption intestinale des graisses; recherches cliniques et expérimentales sur le rôle du foie et du pancréas. Bull. et mém. Soc. méd. d. hôp. de Paris, 1913, s. 3, 36, 72.

(d) Sullivan, M., and Fershtand, J. A. B., Fat absorption; Its value as an index of function of the liver. (Bibliography of recent work.) Arch. Int. Med., 1935, 55, 834.

8. Holt, L. E., Jr., Tidwell, H. C., and Scott, T. F. M., The intravenous administration of fat; a practical therapeutic procedure. J. Pediat., 1935, 6, 151.

9. Sato, G., Verhalten der Ölemulsionen verschiedener Dispersität nach intravenöser Darreichung, mit besonderer Berücksichtigung der Fettembolie der Lunge. Tohoku J. Exper. Med., 1931, 18, 120.

10. (a) Markowitz, C., and Mann, F. C., The rôle of the lung in the metabolism of fat. Am. J. Physiol., 1930, 93, 521.

(b) Nomura, T., Experimentelle Studien über intravenöse Fettinfusion unter besonderer Berücksichtigung parenteraler Ernährung. III. Ablagerunstätte des direkt in die Blutbahn infundierten Fett. Tohoku J. Exper. Med., 1928, 12, 497. 
(c) Holt, L. E., Jr., Tidwell, H. C., and Duff, G. L. Quoted by Holt et al. (8).

11. Gage, S. H., and Fish, P. A., Fat digestion, absorption and assimilation in man and animals as determined by the dark field microscope and a fat soluble dye. Am. J. Anat., 1924, 34, 1.

12. (a) Lemierre et al. (7c).

(b) Bloor, W. R., Gillette, E. M., and James, M. S., Fat metabolism in diabetes. I. The blood lipids in experimental diabetes. J. Biol. Chem., 1927, 75, 61.

(c) Hotta, S., Zur Frage der Resorption parenteral eingeführten emulgierten Fetts. Tohoku J. Exper. Med., 1930, 16, 311.

13. Saxl, P., and Donath, F., Klinische, Experimentelle und pharmakologische Studien über die Abfang- funktion des Retikulo-Endothelialen Systems. Wien. Arch. f. inn. Med., 1926, 13, 7.

14. Lamson, P. D., Gardner, G. H., Gustafson, R. K., Maire, E. D., McLean, A. J., and Wells, H. S., The pharmacology and toxicology of carbon tetrachloride. J. Pharmacol. and Exper. Therap., 1923, 22, 215.

15. Lamson, P. D., and Wing, R., Early cirrhosis of the liver produced in dogs by carbon tetrachloride. J. Pharmacol. and Exper. Therap., 1926, 29, 191.

16. Komatsu, K. In a report by Gomi, A., Baba, T., Kitagawa, R., Onozaki, T., Komatsu, K., Takezawa, H., Hotta, S., Tsuda, K., Aoki, K., and Kimura, S., Experimentelle Untersuchungen über den Fettstoffwechsel. Jap. J. M. Sc., Section VIII, 1934, 3, 47. 